\title{
LITERATURA E REPARAÇÃO: UM PERCURSO
}

\author{
Paloma Vidal \\ Universidade Federal de São Paulo (UNIFESP), São Paulo, SP - Brasil. \\ $<$ palomavidal@yahoo.com>
}

http://dx.doi.org/10.1590/ 0102-64450071-070/96

Este texto surgiu de uma coincidência. Para mim, isso é bastante importante, porque sempre contei muito com os encontros inesperados quanto estou dentro de um projeto ficcional, mas raramente me aconteceu o mesmo na escrita de crítica. Os encontros simplesmente não acontecem do mesmo modo. Eles nunca são realmente inesperados. Sempre tenho a impressão de que têm a ver com alguma conexão estabelecida previamente, que em geral depois me parece um pouco forçada. Na ficção, o acaso parece trabalhar muito mais a meu favor, como se eu o deixasse fazer em paz o seu trabalho.

Convidada por Márcio Seligmann-Silva para o encontro Memória, Arte e Educação em Direitos Humanos, decidi comprar o romance $K$. - Relato de uma busca, que ele mesmo tinha me recomendado, pensando que esse livro poderia me dar alguma pista sobre o tema que nos concernia. Levei o livro para Buenos Aires, para onde viajei pouco depois, e comecei a ler. Fiquei muito tocada com a terceira pessoa criada por Bernardo Kucinski para falar da busca do pai pela filha desaparecida. Esse distanciamento produzido justa- 
mente para poder se aproximar, para criar um espaço entre ele e o outro, que permitisse estar com ele na sua busca solitária. Essa busca solitária que aparece de modo tão concreta nesta cena:

Chegava-se ao grotão caminhando quatrocentos passos regulares em direção aos morros, contados a partir do portão do depósito. Lá estava, de fato, a vereda e no final dela, a rocha esférica de granito descrita pelo jornalista. Ali haviam sido enterrados presos políticos desaparecidos, dissera o jornalista. K. estranhou o solo duro, empedrado, mal aceitando uns poucos tufos de tiririca e capim-barba-de-bode sujos e desbotados. Nenhum sinal de terra revolvida. Talvez isso tenha dado início ao seu desânimo. Também errou ao não chamar ninguém para acompanhá-lo na empreitada. De tanto procurar a filha junto a gente importante, até no estrangeiro, se afastara das ações coletivas, embora é claro toda família fizesse também suas buscas próprias, mobilizasse seus conhecidos, relações de parentesco, mesmo as mais remotas, ou de emprego, isso todos faziam e tinham que fazer; mas há coisas que não se fazem sozinho; só ao atingir o lugar indicado K. percebeu a insensatez da sugestão do jornalista de contratar um trator ali mesmo na cidade e mandar cavar. Como se fosse simples desenterrar um esqueleto ou talvez mais de um sem nenhuma técnica, estragando tudo, sem uma autoridade presente testemunhando e lavrando ata, sem um perito, sem chamar a OAB; não é assim que se faz; vai ver nunca pensara seriamente em escavar; depois de tantos informes falsos, tantas buscas inúteis, já se viciara em buscar apenas por buscar, para não ficar parado; quando estava só, sem fazer nada, eram os piores momentos; a imagem da filha vinha tão forte que doía; por isso, a qualquer palpite, mesmo absurdo, ele se mexia; não foi o caso desse jornalista, pessoa séria, com boas fontes da polícia, famoso por suas reportagens investigativas; depois, o cenário exatamente como ele descrevera; é verdade que 
poderiam ser vítimas de crime comum e não de desaparecidos políticos e ele lá sozinho, de repente mandando um trator revolver o chão, certamente chamaria a atenção; um perigo. Mas não foi por medo que ele nada fez; um pai à procura de uma filha desaparecida não tem medo de nada; pouco lhe importa o que possa acontecer, depois do que já aconteceu. Não, não foi medo, foi desânimo, falta de vontade, exaurido só de chegar e conferir o lugar; e o fato de estar só, é claro (Kucinski, 2014, pp. 97-98).

Se o misto de desânimo e perseverança do pai me remeteu a muitas histórias de familiares de desaparecidos, o que me chamou especialmente atenção neste fragmento foi a "insensatez", que a lucidez do pai não deixa escapar, da ideia de cuidar sozinho da escavação dos ossos, proposta pelo jornalista. "Não é assim que se faz", ele sabe. Sem técnica, sem perito, sem autoridade. Em última instância, sem o amparo que pode dar a ação coletiva, da qual ele também já desistiu, pois nunca chegou a ganhar a dimensão necessária.

Alguns dias após voltar de Buenos Aires, ao abrir minha caixa de e-mail, encontro-me com uma mensagem de um amigo que tem como conteúdo uma frase: apareció el nieto de Estela de Carlotto ${ }^{1}$. A frase se repetiu ao longo de toda aquela terça-feira, 5 de agosto, em mensagens, em telefonemas, nas redes sociais. Na Argentina, ela deve ter sido ouvida também nas ruas, nos cafés, nos supermercados. Meu pai me ligou com a voz emocionada: "apareció el

\footnotetext{
${ }^{1}$ Estela de Carlotto, nascida em 1930, é presidenta da associação de direitos humanos Abuelas de Plaza de Mayo desde 1989. Sua filha Laura Estela Carlotto era estudante de História na Universidad Nacional de La Plata e militava na Juventud Universitaria Peronista. Ela foi sequestrada, estando grávida, em 1977, aos 23 anos. Pelos relatos de testemunhas, Carlotto pôde reconstruir que sua filha chegara a ter o bebê, que foi apropriado pelos militares e teve o nome mudado. Carlotto recebeu diferentes reconhecimentos pelo seu trabalho, entre eles o Prêmio de Direitos Humanos das Nações Unidas e o prêmio Félix Houphouët-Boigny, outorgado pela Unesco.
} 
nieto de Estela de Carlotto." Depois me disse: "vou comprar todos os jornais". Sempre que acontece alguma coisa na Argentina que ele considera muito importante, meu pai vai a uma banca e compra todos os jornais de lá. Lembro que, em Ipanema, onde morávamos quando eu era criança, isso só podia ser feito numa banca específica, em frente a um cinema que já não existe mais, na Visconde de Pirajá, na altura da praça Nossa Senhora da Paz. Não sei o que ele faz com todos esses papéis. Acho que eles terminam sempre no lixo, misturados com jornais novos. Mas meu pai fica muito contente de participar, desse modo, a distância, como se o fato de poder ir a uma banca e comprar esses jornais todos garantisse que, afinal de contas, a distância talvez não seja tão irredutível assim.

Meu pai não tem computador, nem conta de e-mail, nem sabe entrar no Google e muito menos procurar uma notícia num jornal on-line. Mas foi o que eu fiz naquele dia 58 e ao longo da semana que se seguiu. Entrei todos os dias no site do Página 12, abri e imprimi as matérias que saíram sobre o reencontro entre a presidenta da associação das Abuelas de Plaza de Mayo e seu neto, nascido em cativeiro, no ano de 1978, e apropriado pelos militares que o entregaram a um fazendeiro, que, por sua vez, o entregou a um casal que trabalhava para ele, que não podia ter filhos.

A ideia do que vou apresentar surgiu desse encontro entre o livro de Bernardo Kucinski e esse acontecimento. Da dureza do relato sobre a busca solitária de um pai pela filha desaparecida e da alegria compartilhada coletivamente pelo reencontro entre um neto apropriado e a avó militante.

Vou reproduzir aqui alguns fragmentos que apareceram naqueles dias na imprensa argentina. Claudia Carlotto, filha de Estela e titular da Comisión Nacional por el Derecho a la Identidad, dizia numa entrevista: "Não se pode baixar os braços, mas não individualmente, mas coletivamente, 
porque isso não poderíamos ter resolvido de maneira individual nunca"2. O jornalista Luis Bruschtein escrevia: "Laura Carlotto e Oscar Montoya [os pais do neto aparecido] não voltaram à vida. O dano é infinito e irreparável. A recuperação do filho de ambos é uma reparação imensa para esse dano infinito". E prosseguia:

São histórias que têm nomes e sobrenomes, são íntimas e pessoais, mas desde o primeiro dia, desde antes que Laura e Oscar se apaixonassem, é uma história dos argentinos. Há um entorno, uma história política e raízes culturais que os envolvem, os interpelam e lhes falam e constroem suas palavras e sentidos e condicionam seus destinos, os de seu filho e os da avó.

Outro jornalista, Mario Wainfeld: "Estela de Carlotto fala em 'reparação'. Seus olhos brilham, dá gosto vê-la”. E ainda outra, Victoria Ginzberg: "Todos os netos foram um pouco dela. Por isso, ontem, seu neto foi um pouco de todos".

No número 97 da revista Piauí, de outubro de 2014, numa matéria sobre a crise argentina escrita por uma socióloga que mora nos Estados Unidos, Graciela Mochkofsky, retoma-se essa cena do encontro, com um pouco de cinismo e ironia, e misturada às atribulações econômicas pelas quais passou a Argentina recentemente, sob a ameaça do juiz norte-americano Thomas Griesa. Ali deparei com uma frase que me chamou a atenção: "o vitimismo é um dos valores públicos e privados mais importantes da Argentina" (Mochkofsky, 2014, p. 40). Acho que a frase me chamou especialmente a atenção porque no mesmo dia tinha assistido a uma apresentação do crítico e professor da Universidade de Bologna

2 Os trechos que aparecem em português com referências bibliográficas em espanhol foram traduzidos por mim. 
Roberto Vecchi ${ }^{3}$, que tratava precisamente da inscrição da vítima na literatura e na cultura brasileiras. Ele se perguntava, com perplexidade, sobre o caráter compensatório dessas inscrições, que vêm tomar o lugar de uma reparação que nunca chega. "Estela de Carlotto fala em 'reparação'. Seus olhos brilham, dá gosto vê-la”. Era certamente disso que se tratava no encontro entre ela e o neto. De algum tipo de reparação.

A vítima, dizia Roberto Vecchi, no contexto brasileiro, foi muito inscrita literariamente, mas pouco inscrita publicamente. Ele distinguia, nesse sentido, a representação da vítima da política da vítima que poderia operar a reparação. Como entender a dificuldade em inscrever a vítima no âmbito público? Qual a relação entre a ausência dessa inscrição e a profusão de representações literárias - passando pelos Sertões, por Vidas secas, pelos romances-reportagem da década de 1970, pela atual literatura marginal? E ainda: qual a relação entre a ausência de reparação e essas 60 inscrições compensatórias?

Essas perguntas vêm sendo feitas com insistência pela crítica, muito aguda ao descrever a situação atual dessa discussão. "No Brasil ocorreu uma privatização do trauma: apenas os familiares e pessoas próximas às vítimas, além dos próprios sobreviventes, se interessaram por esse tema e investiram na sua memória, na reconstrução da verdade e na busca de justiça”, diz Márcio Seligmann-Silva (2014, pp. 30-31) num texto recente publicado na revista Estudos de Literatura Brasileira Contemporânea. E adverte:

Não se desenvolveu no Brasil, e provavelmente não se desenvolverá, uma cultura da memória com relação àquela ditadura, assim como não se desenvolveu nesse país uma

\footnotetext{
3 A apresentação aconteceu no VI Simpósio Internacional sobre Literatura Brasileira Contemporânea, na Universidade de Brasília, dias 2 a 5 de novembro de 2014, com o título "O lugar da vítima na escrita contemporânea".
} 
cultura da memória em relação ao genocídio indígena, ao de africanos e de afrodescendentes, à escravidão, à ditadura Vargas e à história das lutas no campo e nas cidades no Brasil.

Num texto publicado no mesmo número da revista, encontramos outra reflexão de Roberto Vecchi sobre o tema da reparação, neste caso a partir da história do Araguaia e do romance de Bernardo Kucinski. Ali Vecchi (2014, p. 138) cita a sentença da Corte Interamericana de Direitos Humanos em relação à repressão no Araguaia e mostra como ela apresenta "algumas importantes considerações de ordem conceitual sobre os temas da restituição e da reparação dos danos provocados pelo Estado". Não é possível uma "restituição plena", diz a sentença. Como explica Vecchi,

[...] um dos marcos do terror de Estado praticado no século XX no subcontinente - com a destruição total do corpo do inimigo morto e o ocultamento de seus rastros -, de que o Brasil foi um dos primeiros terrenos empíricos, põe drasticamente em crise e faz colapsar a noção jurídica de restituição ad integrum que é projetada no plano da impossibilidade ou das possibilidades exclusivamente fantasmáticas" (Vecchi, 2014, p. 139).

É a partir dessa impossibilidade, mostra Vecchi (p. 144), que o romance de Kucinski se constitui enquanto "poética restitutiva", aproximando-se de uma "demanda de reparação a partir de um uso poético muito cuidadoso das ausências que são o legado da época autoritária"4.

\footnotetext{
4 Para Vecchi, K. "inaugura uma possibilidade efetiva de escrever a desaparição política", o que se dá através de uma "economia da ausência", que trabalha com "uma ideia de acumulação, de recolha de histórias, fragmentos, contos, como se uma possível homogeneidade narrativa não só fosse inviável mas mesmo que tentada desmoronasse nos restos de qualquer unidade ideal, são o impacto fraturante da experiência traumática" (Vecchi, 2014, p. 143; grifos do autor).
} 
É a partir dessa impossibilidade, gostaria de indicar, que se podem ler algumas falas do neto de Estela de Carlotto, Ignacio/Guido ou Ignacio-Guido. Assim foi escrito seu nome nas primeiras notícias. Nessa barra ou nesse traço, já estão inscritos os dilemas da reparação e da restituição no caso desses sobreviventes. Ignacio foi o nome que sua família adotiva lhe deu. Guido foi o nome que sua mãe escolheu para ele e que sussurrou ao seu ouvido durante as cinco horas que o teve no colo depois do parto. Quando perguntam ao neto, na primeira entrevista que deu, como ele se sente mais à vontade, com Ignacio ou com Guido, responde: "Me sinto mais à vontade na verdade". As falas do neto apontavam o tempo todo para a complexidade da restituição. Quando sua avó o abraça, ele diz "despacito, despacito". "Para mim é diferente do que para eles. Faz dois dias que sei quem sou ou quem não era". As falas do neto apontavam para a necessidade de um tempo de elaboração, para passar desse não saber a um saber, que é muito para62 doxal: "Há coisas que você não sabe que sabe até que chega um indício muito forte e a busca começa". Ou, como ele disse também, havia "umas borboletas no campo da visão", relacionadas sobretudo ao seu desejo de ser músico, que não tinha nada a ver com o ambiente em que foi criado.

Vecchi (2014, p. 145) explica ainda:

A restituição exige complexas operações críticas, inclusive epistemológicas, sobre como, a partir da sua insuficiência e ao mesmo tempo porosidade, pode contribuir a alimentar um trabalho, enlutado e residual, de outro modo impossível, sobretudo na ausência dos despojos ou de restos materiais. Desse modo, se redefinem as práticas, efetivas e simbólicas, de restituição.

Acredito que as falas de Ignacio-Guido tocam, justamente, nessa "insuficiência" e nessa "porosidade". Acredito que elas tocam na importância dessas "complexas operações 
críticas" que, no contexto argentino, fazem parte de um amplo trabalho coletivo de inscrição das vítimas, iniciado ainda durante a ditadura ${ }^{5}$. Acredito, também, nesse sentido, que elas provocam uma reflexão sobre o que a literatura poderia ter a fazer enquanto prática de restituição.

Fico me perguntando se não poderíamos considerar, superposta à tarefa simbólica de elaboração do trauma - que pode ser lida e analisada no âmbito da especificidade das formas literárias de representação, que vão da denúncia mais evidente a formas que problematizam a própria representação - uma outra tarefa, performativa, uma "mise en action do passado", para usar uma expressão de Márcio Seligmann-Silva (2014, p. 28) ${ }^{6}$, no sentido de que a literatura seria efetivamente uma prática, ao lado de outras, como a fotografia, o cinema ou o testemunho, práticas de memória, no contexto mais amplo de um trabalho coletivo, para o qual elas têm uma importante contribuição a dar em termos de como fazer a elaboração traumática a partir das lacunas, das impossibilidades, das fraturas, que aparecem nas falas do neto de Estela de Carlotto.

Estou pensando no papel que a literatura e outras artes podem ter num cenário como o que descreve Ana Amado, num texto intitulado sugestivamente "Órdenes de la memoria y desórdenes de la ficción"7:

\footnotetext{
5 Lembremos que a primeira manifestação pública das Madres de Plaza de Mayo aconteceu no dia 30 de abril de 1977, pouco mais de um ano após o início da ditadura. 6 Trata-se de um comentário ao romance Soledad no Recife, de 2009, de Urariano Mota, híbrido de ficção, reportagem e homenagem, e a mise en action é relacionada por Márcio a certo fracasso do romance enquanto gênero, que, para poder chegar a uma verdade da experiência traumática, precisa ser esgarçado.

7 No livro La imagen justa. Cine argentino y política (1980-2007), Ana Amado (2009) retoma as mesmas questões e o mesmo corpo de filmes tratado neste texto, ao lado de outros, que no livro passam a fazer parte de um percurso bem mais amplo, voltado para a análise da relação entre cinema e política na ditadura e na pós-ditadura, a partir de algumas perguntas que ela resume do seguinte modo: "Quais são as vias de representação de determinados processos histórico-políticos no cinema? Em particular, que procedimentos visuais e narrativos determinados filmes argentinos utilizaram para se referir a esses processos? Que relações são traçadas entre a política formalizada em assuntos públicos, históricos ou institucionais e a estética, que estabelece sua repre-
} 
Protagonistas ao longo das décadas em democracia de uma extensa "cena de produção de linguagens", as diferentes organizações de familiares acompanharam suas demandas formais de justiça no plano jurídico e legal com um repertório notável de recursos expressivos destinados a criar ou representar figurações da memória (Amado, 2004, p. 44).

Me interessa particularmente a ideia de um "acompanhamento" que une as "demandas formais de justiça" a um "repertório notável de recursos expressivos". E me interessa algo fundamental que vem em seguida: "Não se trata aqui de considerar essas práticas poético-testemunhais, voltadas decididamente para o simbólico, sob o prisma sedutor da autoridade redentora da arte” (Amado, 2004, p. 46). É fundamental evitar essa sedução. Entender que o trabalho simbólico de memória tem um papel central, mas que ele não substitui o trabalho efetivo realizado no plano jurídico. 64 Entender que esse papel é central porque, como bem mostram as falas de Ignacio-Guido, como bem assinalou Roberto Vecchi, mesmo havendo alguma reparação, ela se ergue sobre o fundo de uma falta terrível, de um vazio, do irreparável, do irrestituível, sendo aí onde a literatura é efetivamente muito útil, como prática, como mise en action, como o "repertório notável de recursos expressivos", do qual fala Ana Amado.

Nesse mesmo texto, ela analisa dois filmes de duas filhas de desaparecidos e suas estratégias singulares no trabalho de memória, que, num contexto de extensa produção memorialística, vinculada à militância, neste caso especialmente à associação HIJOS (Hijos por la Identidad y la Justicia contra el Olvido y el Silencio), se destacam por se arriscarem em novas formas, registros, discursos, provo-

sentação no plano simbólico? Através de que seleção de imagens e de narrações opera a memória, como prática individual e/ou coletiva, na construção de imaginários estéticos e políticos" (Amado, 2009, p. 12). 
cadores inclusive em relação a essa produção. Gostaria de reproduzir aqui algumas das observações de Ana Amado sobre Los rubios ${ }^{8}$, de Albertina Carri, e Papá Iván ${ }^{9}$, de María Inés Roqué, porque me parece que neles, como em outras produções de filhos da década de 1970, se colocam algumas questões cruciais em relação à memória e suas inscrições.

Queria destacar, em primeiro lugar, alguns pontos mais gerais sobre o trabalho desses filhos que Ana Amado traz à luz: (1) a necessidade de restituir os traços de uma "lenda encabeçada pela figura do pai arrancado pela violência e recuperado a partir do perfil de herói de uma epopeia histórica"; (2) os desvios e interstícios dessa necessidade de restituição, que recuperam também o "rumo de um desejo". Nessa tensão, entre a necessidade de restituição e sua impossibilidade, se constroem os relatos dessas filhas. Nos dois casos, há uma busca de identidade a partir da relação com o pai, que elas carregam no nome próprio com os quais são identificadas como filhas de militantes - de um alto quadro político dos Montoneros, no caso de Albertina, e do fundador das Forças Armadas Revolucionárias, no caso de Maria Inés. Há também, com poéticas diferentes, a necessidade de lidar com o desconsolo pela ausência. Em comum entre essas poéticas, o "testemunho aberto aos dilemas da memória pessoal", e aqui uma palavra-chave, "aberto", marca também a diferença entre as duas, que Ana resume na seguinte distinção: "seguir a pista de uma memória", no caso de Maria Inés, "criá-la", no caso de Albertina; ou, para resumir ainda mais, "reconstrução" no caso de Maria Inés, e "recriação",

8 O filme, com roteiro de Albertina Carri e Alan Pauls e atuação de Analía Couceyro, estreou em 2003, tendo recebido no mesmo ano o prêmio do público de melhor filme, o prêmio do júri paralelo de melhor filme argentino e uma menção especial do júri oficial no Festival Internacional de Cine Independiente de Buenos Aires.

9 Coproduzido pela Argentina e pelo México, país de exílio da diretora com a família, o filme estreou em 2000 e obteve o Coral de melhor documentário no XXII Festival Internacional de La Habana, em 2000, e o Ariel da Academia Mexicana de Cinematografía, em 2003, entre outros prêmios. 
no caso de Albertina. É preciso ressaltar que, se impulsos diferentes guiam os filmes, em nenhum dos dois casos se trata de uma abordagem ingênua, muito pelo contrário: os dois filmes trabalham com as múltiplos dilemas inerentes a cada um desses impulsos.

No caso de Papá Iván, voltamos ao passado para tentar compreender as figuras centrais da militância política dos anos de 1970: a guerra, o combate, a violência, a derrota, a morte. Temos depoimentos de diferentes personagens amigos militantes, a mãe da autora, alunas, familiares; imagens de arquivo, imagens de lugares significativos do passado, imagens da busca no presente, principalmente a paisagem vista a partir da janela do carro ou do trem, que levam a narradora-autora nessa viagem de volta, do presente para o passado, do México, onde foi criada, para a Argentina; viagem esta contada por uma voz em off, com sotaque mexicano, com muita ternura e muito sofrimento, que "desmon66 ta as categorias da ficção e do documentário ao contaminá-las e convocá-las numa zona limite”, que às vezes precisa se interromper pelo choro que ameaça chegar e que termina dizendo: "Siempre me va a quedar la pregunta".

Sobre Los rubios, Amado (2004, p. 70) começa se perguntando o que seria possível dizer a respeito de um filme que mostra uma manada de vacas com maior frequência e nitidez do que as concedidas aos pais, cujo desaparecimento se apresenta como seu tema principal. Nesse sentido, vale lembrar que, referindo-se a esse mesmo filme, no livro Tiempo pasado, Beatriz Sarlo (2005, [s. p.]) comenta:

O filme começa e termina no campo. Na primeira cena, ouve-se uma voz em off, a da diretora, que dá indicações sobre como estribar para andar a cavalo. Na última imagem, vê-se a atriz, que recebia essas indicações na primeira imagem, assistida ainda pela diretora, mas já transformada em jóquei, como se uma aprendizagem tivesse tido lugar, 
não a que o filme se propõe, mas outra: uma aprendizagem de destrezas "normais", que substituiria a fracassada exploração pela memória.

Destaco esta sentença de Sarlo: a "fracassada exploração pela memória”. Nesse livro, que ataca o que chama de "virada subjetiva", é simplesmente impossível para Sarlo ver no filme de Albertina um efetivo trabalho de memória, que aposta na irredutibilidade que separa passado e presente, o eu e o outro, um pai de uma filha, irredutibilidade essa que é do próprio eu, familiar e estranho ao mesmo tempo, daí a centralidade do procedimento de desdobramento da narradora-autora na figura de uma atriz que a representa e com a qual ela conversa o tempo todo no filme.

Gostaria de terminar este percurso falando de um livro que trouxe comigo da viagem a Buenos Aires, chamado Diario de una princesa montonera - $110 \%$ verdad, de Mariana Eva Perez. Antes de seu lançamento em 2012, o livro tinha sido trabalhado desde 2009 num blog, ainda no ar: <www.princesamontonera.blogspot.com>.

Mariana Eva nasceu em 1977 e é filha de desaparecidos. Seus pais militavam, como os de Albertina, no grupo Montoneros. Seu irmão, do qual sua mãe estava grávida quando foi presa, foi apropriado pelos militares e restituído em grande medida graças à militância da irmã. A princesa montonera tem uma história digna da "militonta" que foi durante a adolescência. Esse é o termo "militonta" - com que se refere a si própria várias vezes para indicar uma das passagens nessa sua trajetória de elaboração do passado, cujo resultado mais recente é o romance, escrito a partir do blog e das oficinas literárias da escritora e jornalista Maria Moreno. Essas passagens estão, na verdade, superpostas dentro do livro. A estratégia é a colagem: de sonhos, de e-mails, de imagens, de 
relatos do passado e do presente. O livro é composto de fragmentos, que corresponderiam aos posts do blog, mas cujas datas foram substituídas por títulos. Cito um desses fragmentos, intitulado "A princesa montonera cumpriu com tudo o que indica o protocolo":

Na infância, reverenciou de palavra seus nobres pais ausentes, enquanto intimamente e com culpa temia seu regresso./ Na adolescência, chorou a sorte desditada e odiou os milicos./ Aos vinte, dedicou-se à busca de companheiros militantes, de cativeiro, amigos, ex-namorados. Encontrou-se com os que estavam em Buenos Aires e se correspondeu com os exilados./ Aprendeu a dizer nome de guerra sem que soara a delito, a pôr nele inclusive uma entonação amorosa [...] Foi a tantas homenagens aos companheirosdetidosdesaparecidoseassassinados que já não pode contá-las. Gritou Presente cada vez que os oradores o requereram e escutou com assombro e desagrado o primeiro Agora e sempre, hoje outro clássico./ Em momentos de arrebato kirchnerista precoce, fez a $\mathrm{V}$ da vitória (Perez, 2012, pp. 28-29).

A princesa - como Albertina, como María Inés - busca uma identidade, atravessada pela culpa e até pela raiva em relação aos pais, mas sobretudo pelo desconsolo da ausência. Pela dor da orfandade. Há muitos aspectos que poderiam ser comentados acerca do livro, mas queria focar em um que está bastante mais presente aqui do que nos dois filmes comentados: a vontade de estabelecer comunidades que permitam de algum modo compartilhar essa dor. Nesse sentido, é fundamental o protocolo descrito no fragmento antes citado. Não é casual também que o livro tenha como título o nome de guerra dela própria, muito irônico, sem dúvida, como todos os termos utilizados para nomear a "militôncia", mas nome de guerra, 
enfim. Grande parte do livro é ocupado com os rituais da militância dos filhos de desaparecidos, das quais ela, com maior ou menor distância, dependendo do caso, fez e faz parte: inúmeras reuniões, encontros, homenagens; a confecção de uma placa a ser colocada em frente ao prédio onde seus pais foram sequestrados; os julgamentos aos militares que atuaram na ESMA (Escuela de Mecánica de la Armada, hoje Espacio para la Memoria y para la Promoción y Defensa de los Derechos Humanos), onde sua mãe esteve presa, com a participação como testemunhas de militantes amigos de seus pais, aos quais ela assiste sempre fazendo tricô, que aprendeu com sua avó - e assim por diante.

É dessa experiência coletiva, com todas suas contradições, seus equívocos, seus clichês, que se produz a passagem para a escrita, explicitada na pergunta, tão provocadora como comovente, com a qual eu gostaria, agora sim, de terminar este percurso: "Poderá a jovem princesa montonera torcer seu destino de militonta e devir escritora?".

\section{Paloma Vidal}

é professora de Teoria Literária na Universidade Federal de São Paulo. Escritora e tradutora, é também editora da revista Grumo e da coleção Entrecríticas, da editora Rocco.

\section{Bibliografia}

AMADO, A. 2004. "Órdenes de la memoria y desórdenes de la ficción". In: AMADO, A.; DOMÍNGUEZ, N. (eds.). Lazos de familia. Herencias, cuerpos, ficciones. Buenos Aires: Paidós. . 2009. La imagen justa. Cine argentino y política. (1980-2007).

Buenos Aires: Colihue.

KUCINSKI, B. 2014. K. - Relato de uma busca. São Paulo: Cosac Naify. MOCHKOFSKY, G. 2014. "O eterno naufrágio. Impressões da crise argentina depois de um ano em Nova York". Piauí, n. 97. PEREZ, M. E. 2012. Diario de una princesa montonera - $110 \%$ verdad.

Buenos Aires: Capital Intelectual. 
SARLO, B. 2005. Tiempo pasado. Cultura de la memoria y giro subjetivo. Una discusión. Buenos Aires: Siglo Veintiuno.

SELIGMANN-SILVA, M. 2014. "Imagens precárias: inscrições tênues de violência ditatorial no Brasil”. Estudos de Literatura Brasileira Contemporânea, n. 43, pp. 13-34.

VECCHI, R. 2014. "O passado subtraído da desaparição forçada: Araguaia como palimpsesto. Estudos de Literatura Brasileira Contemporânea, n. 43, pp. 133-49. 


\section{LITERATURA E REPARAÇÃO: UM PERCURSO}

PALOMA VIDAL

Resumo: $\mathrm{O}$ artigo é um percurso através de textos e filmes que abordam a questão da reparação e da memória na Argentina e no Brasil, durante os períodos da ditadura e da pós-ditadura, entendendo-os como práticas de memória que têm um papel central a cumprir no contexto mais amplo de um trabalho coletivo que precisa se dar tanto no plano simbólico como no plano jurídico.

Palavras-chave: Memória; Reparação; Práticas de Memória; Ditadura; Pós-ditadura.

\section{LITERATURE AND REPARATION: AN ITINERARY}

Abstract: The article moves through some texts and films that deal with the question of reparation and memory in Argentina and Brazil, during dictatorship and post-dictatorship periods, understanding them as memory practices, that have a central role to play in the wider context of a collective work that needs to be done both in the symbolic and the legal plans.

Keywords: Memory; Reparation; Memory Practices; Dictatorship and Post-Dictatorship.

Recebido: 02/03/2015 Aprovado: 01/08/2015 